\title{
Evaluation of hardness and surface roughness of two maxillofacial silicones following disinfection
}

Marcelo Coelho Goiato(a)

Aldiéris Alves Pesqueira ${ }^{(b)}$ Daniela Micheline dos Santos ${ }^{(b)}$ Stefan Fiúza de Carvalho Dekon ${ }^{(a)}$

(a) PhD, Professor; (b) Dental Student and trainee - Department of Dental Materials and Prosthesis, School of Dentistry of Araçatuba, São Paulo State University, Araçatuba, SP, Brazil.

\begin{abstract}
The purpose of this study was to evaluate the Shore A hardness and surface roughness of two silicones for maxillofacial prosthetic treatment, under the influence of chemical disinfection and storage. Twenty-eight specimens were obtained, half of which were made of Silastic MDX 4-4210 silicone and, the other half were made of Silastic 732 RTV silicone. The specimens were divided into four groups: Silastic 732 RTV and MDX 4-4210 with disinfection 3 times a week with Efferdent tablets and the same materials without disinfection. The hardness of the materials was analyzed with a Shore A Durometer. The surface roughness was established by a digital portable roughness tester, initially and 2 months after the confection of the specimens. A variance test was applied (2-way ANOVA), followed by Tukey test (the level of significance was set at $1 \%)$. The storage time factor statistically influenced $(\mathrm{p}<0.01)$ the materials' properties of hardness and roughness. MDX 4-4210 (28.59 Shore A, $0.789 \mathrm{Ra}$ ) presented higher values than Silastic $732 \mathrm{RTV}$ (18.08 Shore A, $0.656 \mathrm{Ra}$ ) for both properties. Regarding the disinfection period, there was no significant difference in any of the materials tested.
\end{abstract}

Descriptors: Maxillofacial prosthesis; Disinfection; Hardness.

\footnotetext{
Corresponding author:

Marcelo Coelho Goiato

Faculdade de Odontologia de Araçatuba - UNESP

Departamento de Materiais Odontológicos e Prótese

Rua José Bonifácio, 1193 - Vila Mendonça Araçatuba - SP - Brazil

CEP: 16015-050

E-mail:goiato@foa.unesp.br
}

Received for publication on Nov 01, 2007 Accepted for publication on May 01, 2008 


\section{Introduction}

Maxillofacial prosthetics is the science and art of anatomical, functional, or cosmetic reconstruction by means of artificial replacement of head and neck structures that are missing or defective. Loss of parts of the head and neck can be caused by surgery, trauma, or developmental malformations. Despite the advances in reconstructive and plastic surgery, replacement of the more intricate facial structures still requires the use of man-made materials as external prostheses.

Two major problems are associated with maxillofacial prostheses used to rehabilitate patients with extra-oral-facial deformities, namely: 1) the degradation of static and dynamic physical properties of elastomers, and 2) discoloration of the prostheses in a service environment. ${ }^{1,2}$

The wearing time for facial prostheses averages from 3 months to 1 year. Deterioration is mainly caused by environmental exposure to ultraviolet (UV) light, air pollution, and changes in humidity and temperature. ${ }^{3}$

Chemical disinfection can produce some property alterations of the silicones used as a maxillofacial prosthesis material, so it is important to evaluate these alterations during prosthesis fabrication. Sterilization of dental instruments, equipment and materials has long been suggested and accepted as a requirement in the dental care area. Without this procedure, patients, laboratory assistants and dentists are more susceptible to infections. It is therefore absolutely necessary to use a chemical desinfection material when dealing with prostheses. Furthermore, this chemical solution should not be aggressive to human tissues and must preserve the silicone properties. ${ }^{4}$

To avoid possible infections, an ophtalmic prosthesis should be removed and disinfected periodically with neutral $\mathrm{pH}$ soap and water and then reinserted in the patient's ophthalmic cavity. ${ }^{5}$

In light of the considerations above, the aim of this investigation was to assess the Shore A hardness and roughness of two silicones for use in facial prosthesis, under the influence of chemical disinfection and of storage time in room temperature.

\section{Material and Methods}

Silastic MDX 4-4210 (Dow Corning Corporation, Midland, MI, USA) and Silastic 732 RTV (Dow Corning do Brasil Ltd., Hortolândia, SP, Brazil) were used for manufacturing the specimens.

In order to obtain the specimens, a metallic cylindrical matrix of $3 \mathrm{~mm}$ in height and $30 \mathrm{~mm}$ in diameter was used, together with a ring-shaped metallic frame. The Silastic 732 RTV silicon was confined inside the matrix with the external surface exposed to the environment for 24 hours. According to the manufacturer, the release of acetic acid from this silicone is stabilized 24 hours after the beginning of the polymerization process. The Silastic MDX 44210 material was confined inside the matrix with the external surface exposed to the environment for 3 days since, according to the manufacturer's instructions, the material is partially cured after 24 hours, allowing its handling, but final cure following the release of formaldehyde occurs within approximately 3 days.

After this period, each specimen was carefully separated from the metallic matrix, in order to avoid distortions. Thus, 28 specimens were obtained and divided into 4 groups, with 7 samples in each group:

- Group 1 - Silastic MDX 4-4210 disinfected with effervescent tablets.

- Group 2 - Silastic MDX 4-4210 disinfected with neutral soap.

- Group 3 - Silastic 732 RTV disinfected with effervescent tablets.

- Group 4 - Silastic 732 RTV disinfected with neutral soap.

For Shore A hardness evaluation, a digital durometer (GSD 709 Teclock, Osaka, Japan) was used. The Shore A Durometer executes hardness tests on a rubber in accordance with ASTM D 22401 designation. ${ }^{6}$ The potency of measurement is established between 0 and 100 Shore, with $\pm 1 \%$ tolerance. The load applied is $1.25 \mathrm{Kp}(=12.5 \mathrm{~N})$.

For the surface roughness test, a portable digital roughness tester was used (model RP100, Tonka Sul Americana Ltda., Amparo, SP, Brazil) with $0.01 \mu \mathrm{m}$ accuracy and $6 \mathrm{~mm}$ measurement course. For each specimen, 3 readings were done which, later, were transformed in mean values. The metallic matrix 
roughness was $0.6 \mathrm{Ra}$.

All specimens were stored in a plastic recipient, without covering, on a workbench in a laboratory whose temperature was controlled to $23 \pm 2^{\circ} \mathrm{C}$ during the period of 60 days, receiving artificial light, but without incidence of direct natural light. These conditions simulated those conditions to which prostheses are submitted during their clinical use by patients, in other words, in contact with the environment.

The specimens were disinfected daily with neutral $\mathrm{pH}$ soap and water (control group) or with Efferdent tablets (Pfizer Consumer Healthcare, Morris Plains, NJ, USA) 3 times a week. After the disinfection and 60-day storage periods, new readings were performed, as described previously. After obtaining the results, a variance test (ANOVA) was applied, followed by the Tukey test (the level of significance was set at $1 \%$ ).

Table 1 - Mean values and standard deviations (SD) of Shore A hardness for the tested silicones (Tukey Test - the level of significance was set at $1 \%$ ).

\begin{tabular}{c|c|c|c}
\hline & MDX 4-4210 (SD) & 732 RTV (SD) & p Value \\
\hline Mean value & $28.59(1.2)$ & $18.08(0.72)$ & $0.00001^{*}$ \\
\hline
\end{tabular}

*Statistical Difference $(p<0.01)$.

Table 3 - Mean values and standard deviations (SD) of Shore A hardness for the tested silicones under the influence of chemical disinfection (Tukey Test - the level of significance was set at $1 \%)$.

\begin{tabular}{l|c|c|c}
\hline & $\begin{array}{c}\text { With } \\
\text { Disinfection (SD) }\end{array}$ & $\begin{array}{c}\text { Without } \\
\text { Disinfection (SD) }\end{array}$ & p Value \\
\hline Mean value & $23.09(1.76)$ & $23.58(0.41)$ & $0.12471^{* *}$ \\
\hline
\end{tabular}

${ }^{* *}$ No Statistical Difference $(p<0.01)$.

Table 5 - Roughness $(\mathrm{Ra})$ mean values and standard deviations (SD) for the tested silicones under the influence of chemical disinfection (Tukey Test - the level of significance was set at $1 \%)$.

\begin{tabular}{l|c|c|c}
\hline & $\begin{array}{c}\text { With } \\
\text { Disinfection (SD) }\end{array}$ & $\begin{array}{c}\text { Without } \\
\text { Disinfection (SD) }\end{array}$ & $p$ Value \\
\hline Mean Value & $0.723(0.034)$ & $0.722(0.022)$ & $0.89090^{* *}$ \\
\hline
\end{tabular}

${ }^{* *}$ No Statistical Difference $(p<0.01)$.

\section{Results}

The Silastic 732 RTV and Silastic MDX 4-4210 mean values for Shore A hardness and roughness are shown in Tables 1 through 6 . As can be observed in tables $1,2,4$ and 6 , there were statistically significant differences between the mean values of Shore A hardness and roughness of the silicones tested $(\mathrm{p}<0.01)$. In Tables 3 and 5 , it can be observed that the chemical disinfection did not influence statistically $(\mathrm{p}<0.01)$ the mean values of hardness and roughness.

\section{Discussion}

Shore A hardness is an indicative measure of a material's texture and flexibility. According to Lewis, Castleberry ${ }^{7}$ (1980) and $\mathrm{May}^{8}$ (1978), the ideal values of Shore A hardness would be between 25 and 35 units. As can be seen in Table 1, only the MDX 4-4210 material presented values within this interval. The values obtained for this material are

Table 2 - Mean values and standard deviations (SD) of Shore A hardness for the tested silicones under the influence of storage period (Tukey Test - the level of significance was set at $1 \%)$.

\begin{tabular}{l|c|c|c}
\hline & Initial (SD) & Final (SD) & $p$ Value \\
\hline Mean value & $21.65(1.51)$ & $25.02(1.094)$ & $0.00001^{*}$ \\
\hline
\end{tabular}

*Statistical Difference $(p<0.01)$.

Table 4 - General comparison of roughness mean values (Ra) and standard deviations (SD) for the tested silicones (Tukey Test - the level of significance was set at 1\%).

\begin{tabular}{c|c|c|c}
\hline & MDX 4-4210 (SD) & 732 RTV (SD) & $p$ Value \\
\hline Mean Value & $0.789(0.031)$ & $0.656(0.034)$ & $0.00001^{*}$ \\
\hline
\end{tabular}

*Statistical Difference $(p<0.01)$.

Table 6 - Roughness $(R a)$ mean values and standard deviations (SD) for the tested silicones under the influence of storage time (Tukey Test - the level of significance was set at $1 \%)$.

\begin{tabular}{l|c|c|c}
\hline & Initial (SD) & Final (SD) & $p$ Value \\
\hline Mean Value & $1.214(0.039)$ & $0.231(0.026)$ & $0.00001^{*}$ \\
\hline
\end{tabular}

*Statistical Difference $(p<0.01)$. 
practically coincident with the results of Bell et al. ${ }^{9}$ (1985) and Wolfaardt et al. ${ }^{10}$ (1985). Sanchez et al. ${ }^{11}$ (1992) also compared the physical properties of two silicones for facial prostheses, and observed values below the ideal range (19.9 units). The authors state, however, that this greater softness is desirable and that the materials are a good choice for facial prostheses, even with values below 25 Shore A units. Soft materials are more similar to the human skin, and they may show low values of modulus of elasticity and hardness. ${ }^{12}$ In one of their studies, Moore et al. ${ }^{13}$ (1977) obtained Shore A hardness values of approximately 26.8 units for Silastic MDX 4-4210, and its hardness could be reduced to approximately 18.4 units with the use of silicone fluids.

In the present study, after the storage period, an increase in Shore A hardness was noticed for both materials (Table 2), showing that the storage time produced a significant increase in the hardness of the specimens. This fact is due to the continuous polymerization of those materials, in addition to the evaporation of acetic acid and formaldehyde. ${ }^{14}$

Regarding the influence of chemical disinfection (Table 3), it was observed that this factor did not produce a significant difference in the hardness values of the specimens when compared to the groups without disinfection.

Based on the results presented on Table 4, it is possible to observe that there was a significant difference in roughness when the values of both materials were compared, with MDX 4-4210 showing higher roughness values. This is probably because MDX 4-4210 has a higher filler concentration in its

\section{References}

1. Lemon JC, Chambers MS, Jacobsen ML, Powers JM. Color stability of facial prostheses. J Prosthet Dent. 1995 Dec;74(6):613-8.

2. Yu R, Koran A $3^{\text {rd }}$, Craig RG. Physical properties of a pigmented silicone maxillofacial material as a function of accelerated aging. J Dent Res. 1980;59(7):1141-8.

3. Hanson MD, Shipman B, Verran J, Maryan CJ. Commercial cosmetics and their role in the coloring of facial prostheses. J Prosthet Dent. 1983 Dec;50(6):818-20.

4. Goiato MC, Ribeiro PP, Santos DM, Fernandes AUR, Santos $\mathrm{PH}$, Pellizzer EP. Effect of pigmentation and chemical disin- composition, which promotes a higher roughness. In addition, it has a higher hardness and rupture resistance as it hinders rupture during rupture testing because of the filler added to it, which provides a mechanical interlocking among the different materials of its composition. ${ }^{4}$

As regards the influence of chemical disinfection on roughness (Table 5), it was possible to observe that no significant difference occurred, irrespective of the material and storage period.

Table 6 shows that the roughness $(\mathrm{Ra})$ readings at the initial period presented a higher mean value than that of the matrix $(0.6 \mathrm{Ra})$. After 60 days of storage, the roughness values decreased, irrespective of the material and the chemical disinfection. This can be explained by the continuous polymerization process, which promotes a more complete polymeric chain, making the silicone surface smoother with time. ${ }^{14}$

\section{Conclusions}

The storage time factor had a statistically significant influence on the materials' Shore A hardness and roughness, and MDX 4-4210 presented higher values than Silastic 732 RTV for both properties. Regarding the disinfection period, there was no significant difference for any of the materials.

\section{Acknowledgments}

This investigation was supported by the State of São Paulo Research Foundation (FAPESP), Brazil (Grant number 05/59920-5).

fection on the elastic recovery and tear strength of a silicone maxillofacial prosthetic material. Rev Odontol Unesp. 2004 Oct-Dec;33(4):189-94.

5. Verran J, Maryan CJ. Retention of Candida albicans on acrylic resin and silicone of different surface topography. J Prosthet Dent. 1997 May;77(5):535-9.

6. American Society for Testing and Materials. Designation D 2240-81: standard test method for rubber properties - Durometer hardness. In: Annual book of ASTM standards. Section 9. Philadelphia: American Society for Testing and Materials; 1988. 
7. Lewis DH, Castleberry DJ. An assessment of recent advances in external maxillofacial materials. J Prosthet Dent. 1980 Apr;43(4):426-32.

8. May PD. Maxillofacial prostheses of chlorinated polyethylene. J Biomed Mater Res. 1978 May;12(3):421-31.

9. Bell WT, Chalian VA, Moore BK. Polydimethyl siloxane materials in maxillofacial prosthetics: evaluation and comparison of physical properties. J Prosthet Dent. 1985 Sep;54(3):404-10.

10. Wolfaardt JF, Chandler HD, Smith BA. Mechanical properties of a new facial prosthetic material. J Prosthet Dent. 1985 Feb;53(2):228-34.

11. Sanchez RA, Moore DJ, Cruz DL, Chappell R. Comparison of the physical properties of two types of polydimethyl siloxane for fabrication of facial prostheses. J Prosthet Dent. 1992 May;67(5):679-82.

12. Polyzois GL. Mechanical properties of 2 new addition-vulcanizing silicone prosthetic elastomers. Int J Prosthodont. 1999 Jul/Aug;12(4):359-62.

13. Moore DJ, Glaser ZR, Tabacco MJ, Linebaugh MG. Evaluation of polymeric materials for maxillofacial prosthetics. J Prosthet Dent. 1977 Sep;38(3):319-26.

14. Anusavice KJ. Materiais de moldagem elastoméricos não aquosos. In: Phillips materiais dentários. $10^{\mathrm{a}}$ ed. Rio de Janeiro: Guanabara Koogan, 1998. p. 83-106. 